\title{
Stability and sustainability assessment for the surface failure of various rock slopes excavated along the Konya-Alanya Road segment, Turkey
}

\author{
Ali F. BAYRAM ${ }^{1, *}$, Ahmed I. MOHAMED ${ }^{1}$, Arsalan A. OTHMAN ${ }^{2,3}$ \\ ${ }^{1}$ Konya Technical University, Engineering, and Natural Sciences Faculty, \\ Geological Engineering Dept., 42130 Konya, Turkey \\ ${ }^{2}$ Iraq Geological Survey, Sulaymaniyah Office, Sulaymaniyah, 46001, Iraq \\ ${ }^{3}$ Komar University of Science and Technology, Sulaymaniyah, 46001, Iraq \\ *Corresponding Author: ahmedgeo.63@gmail.com
}

\begin{abstract}
Most of the road networks in Turkey pass through the Hilly region. These roads are constructed through inadequate blasting accompanied by road deterioration or collapse. To date, several researchers in Turkey have not paid adequate attention to the stability analysis of road failures based on the surface orientation of the dominant discontinuity sets. This study, based on the field survey, laboratory measurements, and the use of Dips analyst software, aims to investigate the stability and sustainability of seven different sites that exhibit imminent slope failure along the Konya-Alanya Road (KAR) segment. The sites selected are geologically investigated and geotechnically evaluated using a scan-line survey. We carried out several fields and laboratory measurements. Both Slope Mass Rating (SMR) and Rock Mass Rating (RMR) are quantified and included with rock mass assessment of each slope site. Both the field and laboratory results are integrated by kinematic analysis methods to assess the potential failure of these slopes. The kinematic analysis results demonstrate that the dominant failure forms are planar, wedge, and toppling. $\mathrm{RMR}_{\mathrm{b}}$ results show that some slopes with good rock quality remain unstable and vulnerable to failure despite their fair $\mathrm{RMR}_{\mathrm{b}}$ values. While SMR results show that five of the seven sites are risky, thus, described as partly stable, and the other two are unstable. The results have also implications for the understanding of the causal factors for slope instability, include the discontinuities present in the rock mass, physical, environmental, and meteorological factors influencing them. This study concludes that urgent remedial measures for their long-term stability are recommended.
\end{abstract}

Keywords: Discontinuity; kinematic analysis; slope stability; SMR.

\section{Introduction}

For safe, sustainable road construction and even in post-construction, slope stability analysis of road cuts is still a crucial stage (Hack, 2018). Slope instability particularly in the hilly terrains is often created from unplanned rock slope excavations for construction, infrastructure development, or during the expansion of road networks through blasting, regardless of many significant geological and structural factors like discontinuities (Pradhan \& Siddique, 2020). The interplay of these factors, and weather events (excessive rainfall and snowmelt), are the primary causes of road 
deterioration and many slopes instability issues (Chen et al., 2020).

The major causes of slope instability in the mountainous region generally can be summarized into three causes:

i) Geological and environmental causes (Feng et al., 2020; Othman et al., 2019). ii) Dynamic and morphological causes (Hamza \& Raghuvanshi, 2017).

iii) Anthropogenic activities cause, such as excavation of slope, blasting, land use, etc. (Hack, 2018).

Blasting-triggered excavation can also increase its destabilization for cut slopes' long-term stability.

Slope failures can be classified into three or four forms of failure mechanisms (planar, wedge, toppling, and circular failures) (Hoek \& Bray, 1981; Wyllie, 2017). In many cases, instability in rock slopes and rock mass develops through discontinuities, and these instabilities occur along one or two intersecting planes of discontinuity then forms a wedge type of failure (Hack et al., 2003).

The Taurus Mountains are well known for their geomorphological complexity. It has a landscape resulting from tectonic stress in different directions and intensities (Özgül, 1997). In the Taurus Mountains, rock-slope instability is among the most dangerous environmental threats along the hillsides of the cutting road. For instance, in the present study, the segment of the KAR gives a better connection to the residential area and makes it possible to connect agricultural centers and primary residential areas. However, due to frequent slope instability problems, this road was soon blocked for public use. These problems are mostly due to many causes. Slope instability problems around the study area have generally been studied using GIS, remote sensing, and laser techniques by many researchers (Üstün et al., 2015), but, they have not paid much attention to the geostructural causes and other causative factors in their investigations. This research comes to:

i) investigating the instability of slope at seven sites excavated along the road section. ii) identifying different failure modes in the rock slopes.

iii) pinpoints the causative factors for the failures in these slope sites.

\section{Study area description}

The investigated slope sites along the road segment locate within Taurus Hilly's topographic areas. It begins from Taşkent district (128 km away from Konya city) up to the border of Alanya situated south of Konya city (Figure 1). 


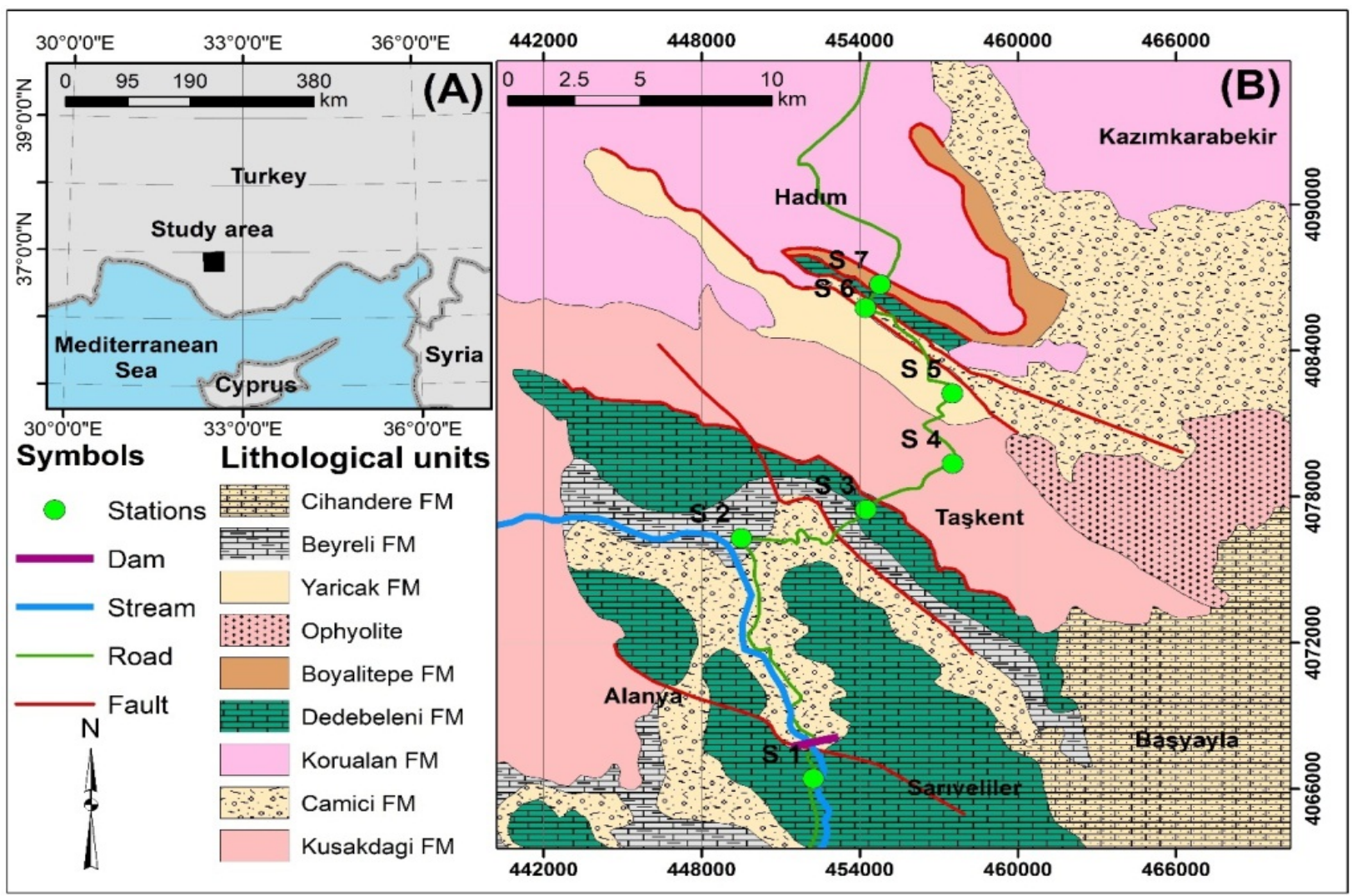

Fig. 1. A) location map, B) geological map of the study area (MTA, 2019).

These slopes are moderate- highly weathered, characterized by narrow valleys with high relief (between $1052 \mathrm{~m}$ and 1403 $\mathrm{m})$, irregular and steep slopes with dip angles ranging between $50^{\circ}$ and $68^{\circ}$, while its average dip direction is $124^{\circ}$ and contain diverse shear zones, and largely man-made rock cut slopes that have been excavated with inadequate blasting, so these slopes pretend to be disturbed and deteriorated. However, these slopes, are recognized at the site as temporarily stabilized.

The annual average rainfall in the road region and around is between $648 \mathrm{~mm}$ and $732 \mathrm{~mm}$ (OGM, 2019).

Geologically, the dominant lithology of the cut slopes investigated along the road and around are mainly constitutes of jointed limestone alternations represented by the
Yarıcak (Carboniferous), Kuşakdağ1 (Permian), Beyreli (Middle Triassic), Dedebeleni (Late Jurassic) formations (Turan, 1990) (Figure 1). Bozkır Unit is also exposed in two sites (S-6 and S-7) represent a diverse rock ranged in age from Triassic to Late Cretaceous (Turan, 1990; Özgül, 1997). It contains a highly deformed pelagic and neritic limestone. It differs in appearance and intensity from one location to another and appears in sections repeatedly.

\section{Methodology and data collection}

For this study, both quantitative and qualitative methods are adopted in the data collection and analysis. In quantitative research, an extensive field survey was performed on recording the important 
geometric, geo-structural features of the rock mass slope. The qualitative approach includes descriptive data based on field-measured observations and data (dependent variables), such as slope face length, slope height, slope angle, slope width, and slope dip/dip directions.

\subsection{Site investigations and field-scale tests}

Site investigation and integrated geophysical investigation play a significant role in stability, designing, economic considerations, and even road preservation (Hack et al., 2003; Adesola et al., 2017; Wyllie, 2017). Field experiments are the first step and are important to understand the characteristics of the landslides (Özfirat et al., 2017; Ahmed \& Al-Dousari, 2013). In site investigations of this study, data on the seven different sites (S1-S7) in the cut slopes are collected through a detailed field survey. In discontinuity survey, joints properties that include orientation, persistence, aperture, spacing, roughness, infilling material properties, and fault attitudes are investigated at seven scan lines of different sites. A total of 212 measurements of joints are recorded in this survey. Other field-scale measurements carried out over the joint surface on-site are for the compressive strength of joint wall (JCS), and the coefficient of joint roughness (JRC). The wall strength has been directly estimated on the joint surfaces using the Schmidt hammer. The (JRC) is also determined by applying the Barton-type wire profilometer to the joint surfaces directly, with the regular profiles suggested by Barton \& Choubey (1977). The related formula for these two important variables along with other shear strength parameters is given in the equation (Eq. 1). $\tau=\sigma n \tan \left[\emptyset_{\mathrm{b}}+\mathrm{JRC} \log 10\left(\frac{\mathrm{JCS}}{\sigma \mathrm{n}}\right)\right] \ldots \ldots$

where $\tau$ is the shear strength; $\sigma \mathrm{n}$ is the normal (vertical) stress; $\varnothing "$ is the base friction angle of the planes; JRC is the Joint roughness coefficient, and JCS is referring to joint compressive strength. Finally, representative rock blocks have been collected from the seven slopes sites to carry out laboratory testing.

\subsection{Laboratory testing}

To identify the geotechnical properties of rocks, several laboratory-scales experiments (unit weight, compressive strength $(\sigma c)$, and shear strength parameters (c, $\phi)$ of rock discontinuity) are undertaken. For these tests, cores are prepared with their appropriate dimensions in the laboratory by I.S.R.M (2007) requirements. The ends of the specimens are sawed as well. Eighteen samples with a diameter of $54 \mathrm{~mm}$ are prepared, measured, then checked with a compass. The averages of samples diameters (D) and lengths (L) have been calculated. Moreover, friction angle value along joint surfaces was evaluated (Hencher \& Richards, 2015).

\subsection{Slope mass rating (SMR) approach.}

SMR rating approach was adopted for this study. It is mainly obtained based on a simple rock mass rating ( $R M R b$; Bieniawski, 1973,1989). $\quad \mathrm{RMR}_{\mathrm{b}}$ is computed according to Bieniawski's (1973) and defined by adding rating values for five parameters are i) Strength of intact rock, ii) Rock Quality Designation (RQD) (measured or estimated), 
iii) Spacing of discontinuities, iv) Discontinuities conditions, and v) Water inflow through discontinuities. RMR has a total range of $0-100$. The SMR rating is estimated mathematically by Eq. 2 (Romana et al., 2003).

$S M R=R M R_{b}+(F 1 * F 2 * F 3)+F 4 . .(2)$

where $\mathrm{RMR}_{\mathrm{b}}$ : basic $\mathrm{RMR}$ index. $\mathrm{SMR}$ is defined by the five parameters of the $R_{M} R_{b}$ rating (Bieniawski, 1989). F1: relates to the parallelism between the dip orientation of joint and slope; F2: defines depending on joint dip within the planar/toppling failure modes; F3: appraises according to the relation between the dips amounts for each the slope and joint; and F4: is a factor relating to the excavation process.

Eq. 2 was used to estimate the final SMR rating values in this study. After that, each of the adjustment factors and the RMRb rating's basic parameters is determined separately. The investigated slope's locations are described and categorized into different classes of instability with their potential risk degrees based on the anticipated percent possibility of slope stability.

\subsection{Kinematic analysis approach}

The stability analysis with the kinematic method used in this study was usually performed with a lower hemispheric projection of Stereo-net and identified according to instructions given by Hoek and Bray (1981), Goodman (1980), and Wyllie (2017).

The method utilized is mostly based on data acquired from a survey with a scan line, as well as some laboratory testing. Slope-joint orientations, slope geometry, and friction angle along discontinuity planes were among the information collected. In this methodology, at first, poles of the collected slope data are clustered by Stereo-net using DIPS 7.0 analyst software (Rocscience, 2010).

Second, based on the clustered data on the slope, the spatial distribution of all major discontinuity planes is presented. Then, the slope stability analysis is carried out accordingly.

\section{Results}

A total of 212 joints have been documented at seven different locations. Table 1 summarized the prevailing joint orientations data for these locations.

Table 1. Joint-slope data measured on slope faces and used as inputs to the kinematic analyzes.

\begin{tabular}{|c|c|c|c|c|c|c|}
\hline \multirow{2}{*}{$\begin{array}{l}* \mathrm{~d}-\mathrm{d} \\
=\mathrm{dip} \\
\text { direct }\end{array}$} & \multirow{2}{*}{$\begin{array}{l}\text { Slope } \\
\text { (d-d/da) }\end{array}$} & \multirow{2}{*}{$\begin{array}{l}\text { Bedding plane } \\
\qquad(\mathrm{d}-\mathrm{d} / \mathrm{da})\end{array}$} & \multicolumn{3}{|c|}{ Orientation for joints } & \multirow[b]{2}{*}{$\begin{array}{c}\text { Residual }\left(\phi_{\mathrm{r}}\right) \\
\left(^{\circ}\right)\end{array}$} \\
\hline & & & J1 (d-d / da) & $J 2(d-d / d a)$ & J3 (d-d / da) & \\
\hline S-1 & $100 / 60$ & $210 / 34-35$ & $290 / 47$ & - & - & 29 \\
\hline S-2 & $300 / 56$ & $180 / 30-35$ & $282 / 10$ & $092 / 32$ & $196 / 27$ & 29 \\
\hline S-3 & $090 / 57$ & $046 / 61$ & $224 / 34$ & $072 / 33$ & $175 / 24$ & 31 \\
\hline S-4 & $280 / 58$ & $270 / 40$ & $217 / 35$ & $06 / 34$ & $167 / 30$ & 36 \\
\hline S-5 & $087 / 63$ & - & $286 / 06$ & $222 / 38$ & $165 / 27$ & 31 \\
\hline S-6 & $270 / 48$ & $310 / 20-40$ & - & 094/04 & $190 / 23$ & 37 \\
\hline S-7 & $185 / 78$ & $230 / 40$ & $278 / 12$ & - & $189 / 27$ & 30 \\
\hline
\end{tabular}


These data are examined in detail and used later in the analysis using Dips software. Furthermore, the results of field and laboratory tests associated with the shear strength parameters $(\mathrm{c}, \phi)$ along with JRC and JCS are summarized in Table 2.

Table 2. Field and laboratory findings of shear test of discontinuity conditions in this study.

\begin{tabular}{|c|c|c|c|c|c|c|c|c|}
\hline \multirow{3}{*}{ Sites } & \multirow{3}{*}{$\begin{array}{l}\text { Geologic } \\
\text { Unit }\end{array}$} & \multirow{3}{*}{$\begin{array}{l}\text { Rock } \\
\text { Type }\end{array}$} & \multicolumn{2}{|c|}{ Field } & \multicolumn{4}{|c|}{ Laboratory } \\
\hline & & & \multirow{2}{*}{$\begin{array}{l}\text { JRC } \\
\text { Avg. }\end{array}$} & \multirow{2}{*}{$\begin{array}{c}\mathrm{JCS} \\
(\mathrm{MPa})\end{array}$} & \multicolumn{2}{|c|}{ Cohesion (Kpa) } & \multicolumn{2}{|c|}{ Friction Angle (deg.) } \\
\hline & & & & & $\begin{array}{l}\text { Peak } \\
\left(c_{p}\right)\end{array}$ & $\begin{array}{c}\text { Residual } \\
\left(c_{\mathrm{r}}\right)\end{array}$ & Peak & $\begin{array}{l}\text { Residual } \\
\left(\phi_{\mathrm{r}}\right)\end{array}$ \\
\hline S- 1 & Dedebeleni & Limestone & 8 & 49.5 & 648 & 462 & 34 & 30 \\
\hline S- 2 & Beyreli & Sandstone & 13 & 47.5 & 1030 & 765 & 31 & 29 \\
\hline S- 3 & Beyreli & Limestone & 11 & 46.5 & 963 & 621 & 31 & 29 \\
\hline S- 4 & Kuşakdağ 1 & Limestone & 10 & 58 & 1638 & 1336 & 33 & 31 \\
\hline S- 5 & Yarıcak & Limestone & 12.5 & 53 & 2014 & 1659 & 38 & 36 \\
\hline S- 6 & Boyalitepe & Limestone & 15 & 63 & 909 & 816 & 33 & 31 \\
\hline S- 7 & Korualan & Limestone & 17 & 64 & 1419 & 1099 & 39 & 37 \\
\hline
\end{tabular}

Likewise, other results of laboratory tests performed on the rock material (core) during this analysis, along with their statistics, are shown in Table 3.

Table 3. Laboratory tests results of some geomechanical properties for this study.

\begin{tabular}{cccccc}
\hline Property & Tests Number & Min. & Max. & Mean & Sta. Dv. \\
\hline $\begin{array}{c}\text { Compressive strength (Uniaxial) } \\
\text { UCS, Mpa }\end{array}$ & 51 & 1.95 & 2.98 & 2.53 & 0.89 \\
$\begin{array}{c}\text { strength (point load test) index } \\
(\text { Is }(50), \mathrm{MPa})\end{array}$ & 74 & 66.2 & 98.60 & 70.73 & 5.21 \\
Unit weight $(\gamma, \mathrm{kN} / \mathrm{m} 3)$ & 27 & 25.59 & 26.18 & 25.98 & 0.45 \\
\hline
\end{tabular}

The data in Tables 1 and 2 were utilized as input parameters in the generation of the data clustering of discontinuity planes, such as a pole, rose map, and contour diagrams (Figure
2). Most of the rock masses of the cut slopes analyzed are intersected with three joint sets (J1, J2, and J3) (Figure 2). 

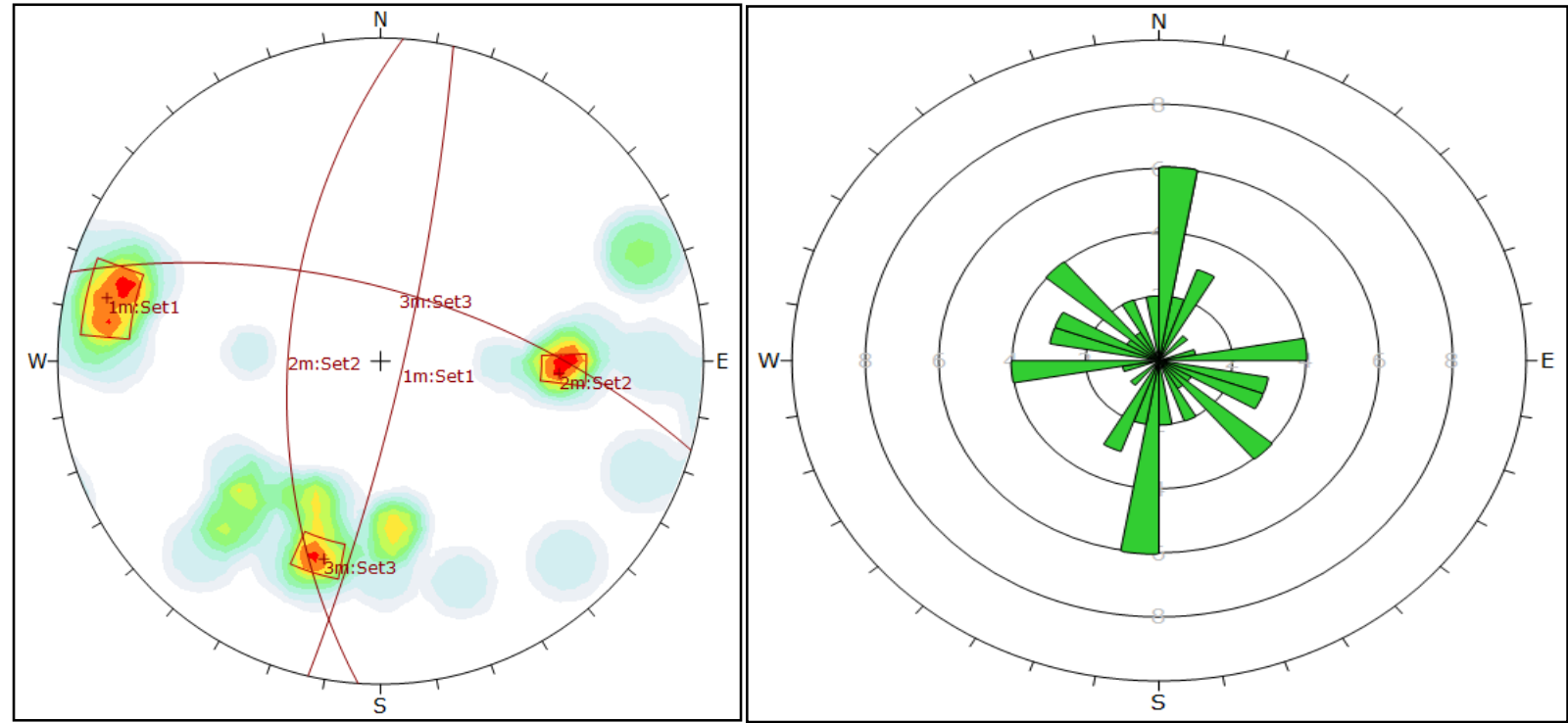

Fig. 2. Determining prevailing joint sets, through rose (left) and contour diagrams (right) using Dips analyst software.

Then, the geometric properties (spacing, persistence, aperture, and roughness) of the discontinuities are examined in the field survey as well and statistically represented with the chart in Figure 3. The plotted discontinuity spacing versus cumulative frequency histogram generally very closed spacing fall between $0.6 \mathrm{~m}$ and $2 \mathrm{~m}$ (Figure 3a). Meanwhile, the average discontinuities aperture range is between $0.5 \mathrm{~mm}$ and $10 \mathrm{~mm}$ that is partly open to the wide near-surface (Figure 3b).
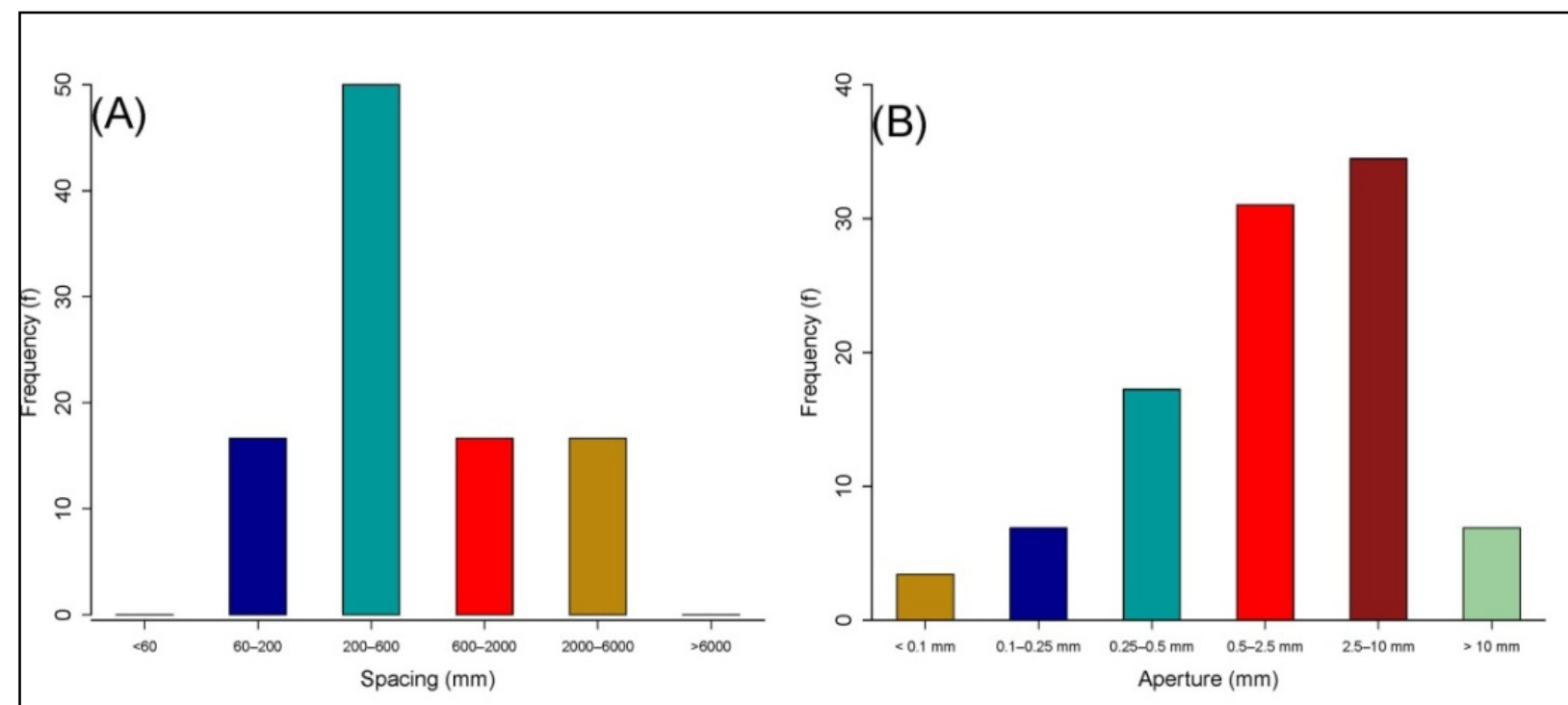

Fig. 3. The statistical distribution of discontinuity spacing (a), and aperture (b) were measured in this study. 
The persistence of discontinuities ranges between $3 \mathrm{~m}$ and $10 \mathrm{~m}$, it may be less at depth, thus, it also classifies as medium-high persistence. In addition, discontinuity asperities were already evaluated as undulating rough to smooth with a roughness coefficient (JRC) ranging between 8 and 17 (Table 2). Finally, the slope stability is supplemented accordingly as given in Figure 4.

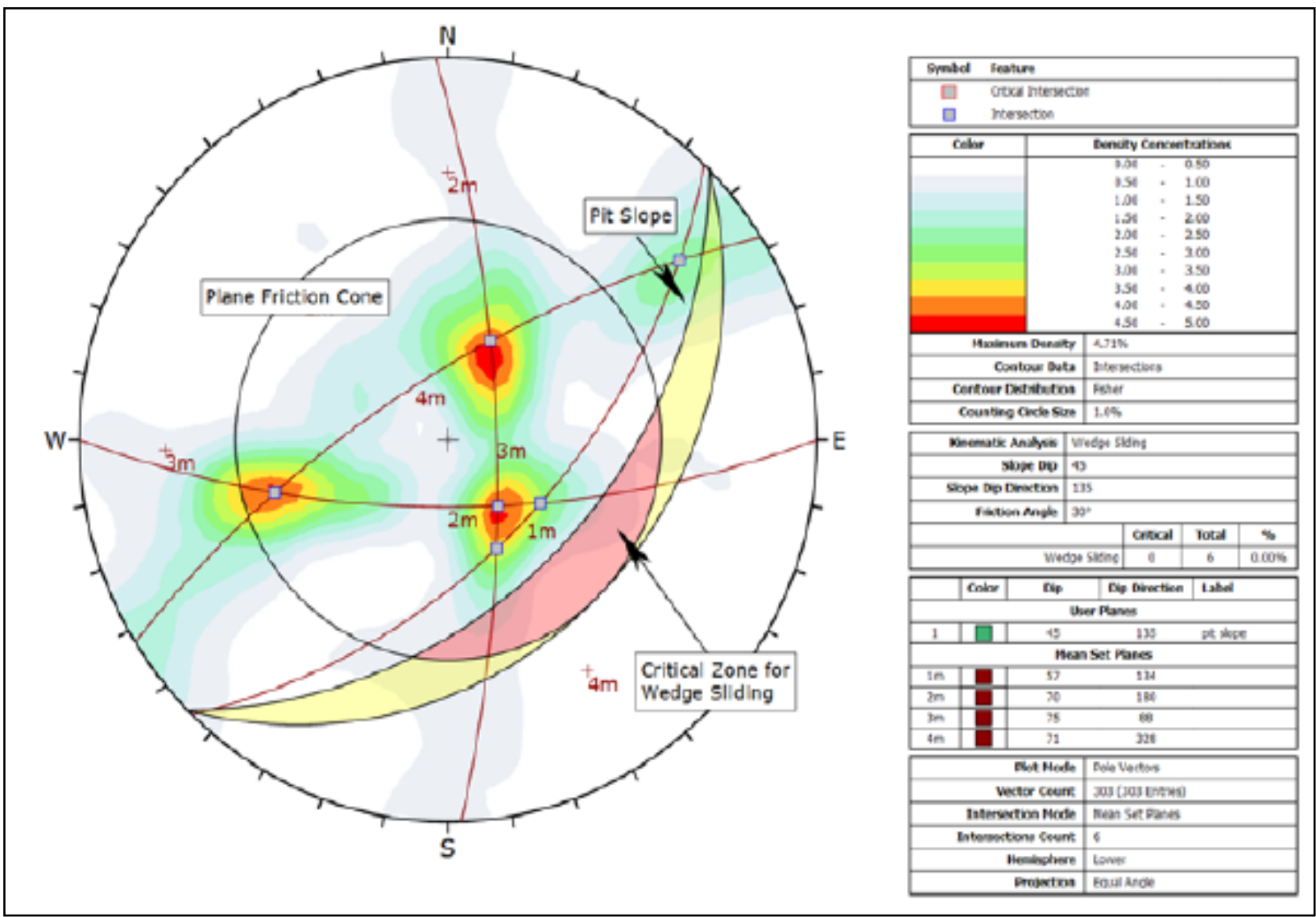

Fig. 4. Kinematic slope stability analysis for present study using Dips analyst.

The kinematic analysis illustrated in Figure 4 is used to determine the probability of each failure type and its proportion of occurrence for each site, which is then summarized in Table 4. 
Table 4. Summary of kinematic analysis results for this study, according to Goodman's (1980) guidelines.

\begin{tabular}{|c|c|c|c|}
\hline \multirow{2}{*}{ Sites } & \multicolumn{3}{|c|}{ Failure risk probability (\%) } \\
\hline & Planar sliding & Wedge sliding & Flexure toppling \\
\hline \multirow{2}{*}{ S- 1} & *All 21.21 & \multirow{2}{*}{${ }^{*} \mathrm{I}_{1} 290 / 47(27.82)$} & \multirow{2}{*}{ All 6.25} \\
\hline & Set (1) 100 & & \\
\hline \multirow{2}{*}{ S- 2} & \multirow{2}{*}{0.0} & \multirow[t]{2}{*}{$\mathrm{I}_{2-3}, 320 / 46(25.88)$} & All 11.43 \\
\hline & & & Set (1) 100 \\
\hline S- 3 & 0.0 & I1, I2 (5.71) & All 17.14 \\
\hline \multirow{2}{*}{ S- 4} & All 11.3 & $\mathrm{I}_{1-2}, 021 / 54(15.29)$ & \multirow{2}{*}{ All 2.86} \\
\hline & Set (1) 100 & & \\
\hline \multirow{2}{*}{ S- 5} & All 5.71 & $\mathrm{I}_{1-2}, 021 / 49(20.71)$ & \multirow{2}{*}{ All 2.86} \\
\hline & Set (1) 33.33 & $\mathrm{I}_{2-3} 033 / 51(20.71)$ & \\
\hline \multirow{2}{*}{ S- 6} & \multirow{2}{*}{ All 2.86} & $\mathrm{I}_{2}$-slope $303 / 42(3.19)$ & \multirow{2}{*}{$\begin{array}{c}\text { All } 14.29 \\
\text { Set (1) } 25.0\end{array}$} \\
\hline & & \multirow{3}{*}{$\mathrm{I}_{2}$-slope, $139 / 7$ (9.02) } & \\
\hline \multirow{2}{*}{ S- 7} & \multirow{2}{*}{ All 2.70} & & All 16.27 \\
\hline & & & Set (1) 100 \\
\hline
\end{tabular}

* All: implies that both geometrical and weather influences together affect the slope instability, $\mathrm{I}_{2-3}$, 320/46: refers to the orientations of the line resulting from the intersection of two joints.

The kinematic analysis approach results inserted in Table 5 were analyzed and discussed in detail in the discussion section.

Table 5. Summary of failure probable mode inferred with kinematic analysis.

\begin{tabular}{cccc}
\hline Sites & \multicolumn{2}{c}{ Failure mode } \\
\cline { 2 - 4 } & Planar & Wedge & Toppling \\
\hline S- 1 & *es & Yes & No \\
S- 2 & No & Yes & Yes \\
S- 3 & No & No & Yes \\
S- 4 & Yes + & Yes & No \\
S- 5 & Yes & Yes & No \\
S- 6 & No & No & Yes \\
S- 7 & No & Yes + & Yes \\
\hline
\end{tabular}

* Yes: Failure occurs; $\mathrm{Yes}^{+}$: failure probability $>10 \%$; and No: for failure probability $<5 \%$.

In addition to kinematic analysis, site measurements relating to the RQD, Uniaxial Compressive Strength (UCS), joint characteristics, and groundwater conditions are utilized to estimate the perusal RMRb and
SMR rating values in this study (Table 6). The SMR values are also quantified based on the $\mathrm{RMR}_{\mathrm{b}}$ perusal rating, the joint and slope adjustment factors (F1, F2, F3, and F4) for each site slope. Based on the all obtained 
results, the stability description for each slope is provided in Table 7 .

Table 6. $\mathrm{RMR}_{\mathrm{b}}$ and $\mathrm{SMR}$ quantification rating outcomes for all the slopes.

\begin{tabular}{|c|c|c|c|c|c|c|c|c|}
\hline \multirow{3}{*}{ Sites } & \multirow{3}{*}{$\mathrm{RMR}_{\mathrm{b}}$} & \multicolumn{6}{|c|}{$\begin{array}{l}\text { SMR** rating values calculated for } \\
\text { each discontinuity set }(\mathrm{J} 1, \mathrm{~J} 2 \text {, and } \mathrm{J} 3)\end{array}$} & \multirow{3}{*}{$\begin{array}{l}\text { SMR }{ }^{* *} \text { slope's } \\
\text { average }\end{array}$} \\
\hline & & \multicolumn{2}{|c|}{ J1 } & \multicolumn{2}{|c|}{$\mathrm{J} 2$} & \multicolumn{2}{|c|}{$\mathrm{J} 3$} & \\
\hline & & Ky & Dv & $\mathrm{Ky}$ & Dv & Ky & Dv & \\
\hline S-1 & 54.4 & 28.4 & 64.4 & 56.75 & 64.4 & 64.4 & 53.5 & 55.30 \\
\hline S-2 & 52.5 & 54.5 & 50.75 & 54.5 & 50.75 & 55.4 & 50.75 & 52.67 \\
\hline S-3 & 49.2 & 56.3 & 53.45 & 57.2 & 53.45 & 57.2 & 53.45 & 55.17 \\
\hline S-4 & 51.5 & 58.6 & 58.6 & 59.5 & 34.5 & 59.5 & 55.57 & 55.16 \\
\hline S-5 & 51.5 & 42.6 & 39.75 & 42.6 & 39.75 & 43.5 & 33.5 & 40.28 \\
\hline S-6 & 50.5 & 42.4 & 42.4 & 41.5 & 42.4 & 41.5 & 42.4 & 39.10 \\
\hline S-7 & 57 & 51.0 & 31.5 & 41.5 & 45.25 & 51.0 & 39 & 44.65 \\
\hline
\end{tabular}

* Ky: Planar, **Dv: Toppling, and ***kky: Wedge failure; SMR** $=$ RMR $_{\text {basic }}+($ F1.F2.F3) +F4

Table 7. Stability definition based on SMR values and according to Romana (1985).

\begin{tabular}{ccccccc}
\hline $\begin{array}{c}\text { Sites } \\
\text { No. }\end{array}$ & SMR & $\begin{array}{c}\text { Class } \\
\text { No. }\end{array}$ & $\begin{array}{c}\text { Slope } \\
\text { descriptio } \\
\mathrm{n}\end{array}$ & Stability & $\begin{array}{c}\text { Inferred failure from SMR } \\
\text { rating }\end{array}$ & $\begin{array}{c}\text { Possibility of } \\
\text { slope failure } \\
\text { stability } \%\end{array}$ \\
\hline S -1 & 55.30 & III & Normal & $*$ PS & P/W & 40 \\
S -2 & 52.67 & III & Normal & PS & P/W & 40 \\
S -3 & 55.17 & III & Normal & PS & P/W & 60 \\
S - 4 & 55.16 & III & Normal & PS & P/W & 40 \\
S -5 & 40.28 & IV & Bad & $* *$ US & Big planar or toppling & 0 \\
S -6 & 39.10 & IV & Bad & $* *$ THE & Planar & 20 \\
S -7 & 44.65 & III & Normal & PS & P/W & 40 \\
\hline * PS: Partially stable;**US: unstable; P/W: Planar along some joints or wedge failure.
\end{tabular}

* PS: Partially stable; **US: unstable; P/W: Planar along some joints or wedge failure.

\section{Discussion and assessment}

In the context of this study, in addition to using kinematic and SMR ratings, other impacts contributing to slope instability have also been discussed and attempted to be included in the final sustainability assessment. 


\subsection{Kinematic analyses}

Based on the kinematic analysis results, it can be argued that three site slopes (S-1, S-4, and S-5) satisfy the required conditions for the planar failure occurrence. The dip orientation of joints and slope face, beddings plane is almost in parallel $\left( \pm 20^{\circ}\right)$, and the daylight conditions resulting from the $\mathrm{J} 1$ critical joint, thus, a planar failure occurrence is predicted in these three cut slopes, which may be due to sliding of the blocks along any single joint line. Unlike, no planar failure is expected for S-2 and S-3 cut slopes, this might due to the angular geometric $\left(>20^{\circ}\right)$ relationship between the face of slope and prevalent discontinuity sets. In comparison, it should be noticed that the wedge failure probability percentage is substantially higher than that of planar and toppling failures.

The main reason for wedge failure formation can be due to the three dominant sets of joints $(\mathrm{J} 1, \mathrm{~J} 2$, and $\mathrm{J} 3)$, or to the appearance of a shear zone within the rock masses. This implies that the potential mode of failure is mainly depending on the nature of discontinuities and shear strength along with them. For example, a wedge failure is likely to occur on certain site slopes although it has one prevailing joint set, this may be due to shear zones' presence or stress cracks within the rock mass itself (Figure 5).

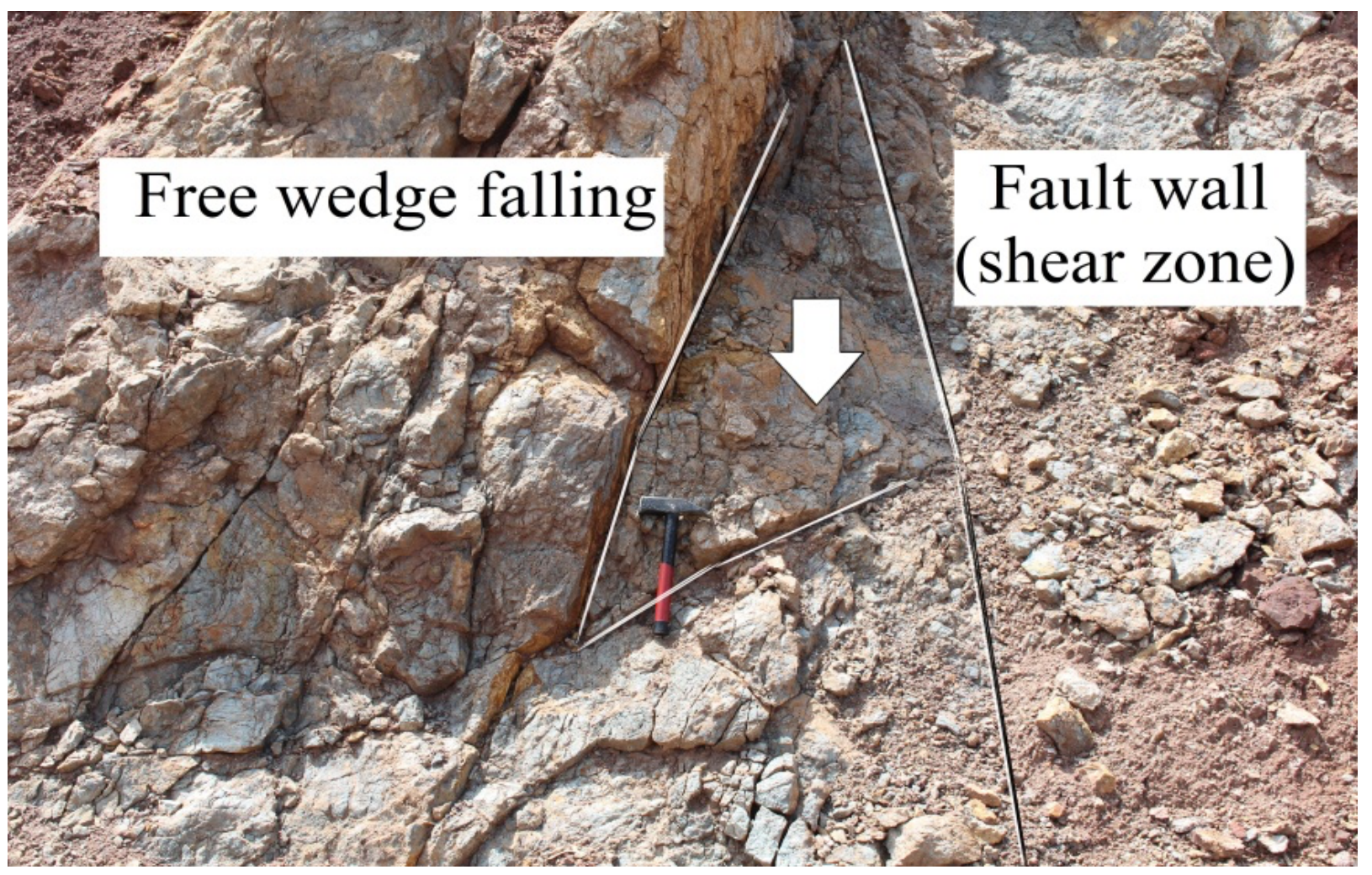

Fig. 5. Structurally- controlled (wedge) failure formed by shear zones in Bozk1r units in the present study. 
On contrary, no circular failure is expected in all site slopes, this may be due to sliding surface along discontinuities (Wyllie, 2017), or because of the steep dipping of discontinuities towards slope face, as well as a critical high of slopes and irregular slope face that can interfere with other triggering factors, to failure in slope. These conditions are therefore sought to be researched in detail than summarized with the term "All" in the legend of Table 4.

\subsection{SMR rating}

Table 6 shows that despite their high RMRb values, slopes belonging to Bozkr units with good rock quality remain unstable and vulnerable to failure. S-6, for example, although having good RMRb values (50.4), sounds like a very problematic slope site.

Table 7, shows that 5 of the slopes are partly stable or under the risk of failure. However, practically this means that most of the slopes under investigation are partially stable at the present, but could lose their strength over time under various external effects. Thus, several further failures are likely to occur unless remedial action is taken.

Other hands, The failure modes indicated using SMR rating are varied slightly from those inferred from kinematic analysis, which could be due to a variety of factors including lithology, structure, and excavation method effects on those slopes.

\section{Conclusion}

This research project has helped in identifying rock slopes instability with its associated problems in the KAR. thus, will help in mitigating the slope failure reasons and provide security for road users. This study concludes that most of the seven investigated slopes are partially stable. Thus, remedial action is very urgently needed to prevent any potential degradation of the remaining major blocks. Moreover, our results confirm that the findings obtained from the kinematic analysis fit well with the current site conditions. Hence, kinematic stability research is crucial to study the sustainability of essential infrastructures like roads. This instability may be due to reduced normal stress and increased shear stress along discontinuity planes.

We remarked that the SMR does not consider the slope height. It is only taking into account the orientations of discontinuity in the failed mass, which is the main drawback in slope stability assessment using this rating. Finally, we are convinced that a thorough analysis of the investigated slopes by the equilibrium limit technique would be useful for a better understanding of the possible failure mode, failure surface conditions, and impact of joints leading to unstable blocks. 


\section{Author's contributions}

Ali Ferat Bayram delineated the research and supported the evaluation and debate. Ahmed Ibraheem Mohamed has carried out fieldwork, data collection, and laboratory testing. Arsalan Ahmed Othman assisted with the manuscript writing, preparation, and discussion. The manuscript was reviewed and revised by all the authors.

\section{Funding information}

This research has been financially sponsored by the Science Research Projects Support Foundation (BAP) of Konya Technical

\section{References}

Adesola, A.M., Ayokunle, A.A. \& Adebowale, A.O. (2017). Integrated geophysical investigation for pavement failure along a dual carriageway, Southwestern Nigeria: a case study. Kuwait Journal of Science, 44(4).

Ahmed, M., \& Al-Dousari, A.M. (2013). Geomorphological characteristics of the UmRimam depression in northern Kuwait. Kuwait Journal of Science, 40(1).

Barton, N. \& Choubey, V. (1977). The shear strength of rock joints in theory and practice. Rock mechanics journal.10(1-2):154.

Bieniawski, Z.T. (1973). Engineering classification of jointed rock masses. Civil Engineer in South Africa. 15(12)193-201.
University, Konya, Turkey.

\section{ACKNOWLEDGMENTS}

The authors would like to offer their great thanks and deep gratitude to Prof. Dr. Ihsan Özkan from Konya Technical University (Turkey), Dr. Majid Saeed from the Missouri University of Science and Technology (USA), and Neil Bar from Gecko Geotechnics (Australia) for their valuable contributions and helpful feedback that improved this manuscript.

Bieniawski, Z.T. (1989). Engineering rock mass classifications: a complete manual for engineers and geologists in mining, civil, and petroleum engineering: John Wiley \& Sons.

Chen, L., Zhang, W., \& Zheng, Y. (2020). Stability analysis and design charts for overdip rock slope against bi-planar sliding. Engineering Geology, 275, 105732.

Feng, S., Liu, H., \& Ng, C.W. (2020). Analytical analysis of the mechanical and hydrological effects of vegetation on shallow slope stability. Computers and Geotechnics, $118,103335$.

Konya Regional Directorate of Forestry (OGM) (2019). Seasonal spatial rainfall report. p18. 
Goodman, R. (1980). Introduction to Rock Mechanics, edited by John Wiley and Sons. New York.

Hack, R. (2018). Slope stability \& weathering by classification; SSPC, RMR, GSI. the Rock mass description in the Bentheimer.

Hack, R., Price, D., \& Rengers, N. (2003). A new approach to rock slope stability- a probability classification (SSPC). Bulletin of Engineering Geology and the Environment.62(2): 167-184.

Hamza, T. \& Raghuvanshi, T.K. (2017). GIS-based landslide hazard evaluation and zonation-a case from Jeldu District, central Ethiopia. Journal of King Saud UniversityScience, 29 (2):151-165.

Hencher, S. \& Richards, L. (2015). Assessing the shear strength of rock discontinuities at laboratory and field scales. Rock mechanics and rock engineering. 48 (3):883-905.

Hoek, E, \& Bray, J. (1981). Rock Slope Engineering. The Institutional of Mining and Metallurgy: London: 356h.

I.S.R.M. (2007). The complete ISRM suggested methods for rock characterization, testing, and monitoring: 1974-2006: International Soc. for Rock Mechanics, Commission on Testing Methods, 628 p.

MTA (2019). General Directorate of Mineral and Research Explorations, Turkey, Geological maps of Turkey, the scale of $1: 100,000$.
Othman, A.A., Al- Maamar, A.F., AlManmi, D.A.M., Liesenberg, V., Hasan, S., Al-Saady, Y.I., Shihab, A.T., Khwedim, K. (2019). Application of DInSAR-PSI Technology for Deformation Monitoring of the Mosul Dam, Iraq. Remote Sensing,11(22), 2632.

Özgül, N. (1997). Bozkır-Hadim-Taşkent (Orta Toroslar'ın kuzey kesimi) dolayında yer alan tektono-stratigrafik birliklerin stratigrafisi. Maden Tetkik ve Arama Dergisi, 119.

Özfirat, K.M., Malli, T., Ozfirat, P.M., \& Kahraman, B. (2017). The performance prediction of roadheaders with response surface analysis for underground metal mine. Kuwait Journal of Science, 44(2).

Pradhan, S.P.\& Siddique, T. (2020). Stability assessment of landslide-prone road cut rock slopes in Himalayan terrain: A finite element method based approach. Journal of rock mechanics and geotechnical engineering, 12 (1), 59-73.

Rocscience. (2010). Dips user's manual. Rocscience incorporation, Toronto, Canada, p 27.

Romana, M. (1985). New Adjustment Ratings for Application of Bieniawski Classification to Slopes. International Symposium on the Role of Rock Mechanics in Excavations for Mining and Civil Works, International Society of Rock Mechanics, Zacatecas, 49-53.

Romana, M., Serón, J.B., \& Montalar, E. (2003). SMR geomechanics classification: 
application, experience, and validation. Paper presented at the 10th ISRM Congress.

Turan, A. (1990). Geology, stratigraphy and tectonic development of Hadim (Konya) and Southwest in the Taurus Mountains, Dissertation, Selcuk University, Turkey, p240.

Üstün, A., Tuşat, E., Yalvaç, S., Özkan, İ., Eren, Y., Özdemir, A., \& Doğanalp, S. (2015). Land subsidence in Konya Closed Basin and its spatio-temporal detection by GPS and DInSAR. Environmental earth sciences, 73(10), 6691-6703.

Wyllie, D.C.\& Mah, C.W. (2004). Rock slope engineering-civil and mining. 4th Edition, Spoon Press: New York.

Wyllie, D.C. (2017). Rock slope engineering: civil applications: CRC Press, Boca Raton, 620 p.

Submitted: $\quad 14 / 10 / 2020$

Revised: $\quad 08 / 12 / 2020$

Accepted: $\quad 09 / 12 / 2020$

DOI: $\quad 10.48129 /$ kjs.v48i4.10679 